\title{
Training institutes and training in official statistics in Africa: An overview
}

\author{
Hugues Kouassi Kouadio \\ Centre of Excellence in Statistical Training and Ecole Nationale Supérieure de Statistique et d'Economie Appliquée \\ (ENSEA), Avenue des Grandes Ecoles, Cocody, 08 BP 03 Abidjan 08, Côte d'Ivoire \\ E-mail: hkouadio@ensea.ed.ci
}

\begin{abstract}
The training offer of official statistics in statistical training institutes has been constantly evolving as it adapts to the statistical environment and technological developments. Based on a literature review and the mobilisation of curricula and programmes offered by statistical training centres in Africa, this paper presents the current situation of training in official statistics as well as the challenges to be faced. Despite harmonisation efforts, there are still differences between language areas and training types. Engineer and vocational statistical training are better suited to the needs of National Statistical Institutes than university training. It is essential that the training of statisticians is strategically thought out so that they can be reactive and dynamic in the face of changes and upheavals they will be confronted with in the context of data revolution and big data. Their training should reinforce the statistical literacy dimension with a view to reducing the gap between producers and users.
\end{abstract}

Keywords: Training institute of statistics, official statistics, Africa, curricula, STPA, Agrost, GIST, RESA

\section{Introduction}

Harmonised and quality statistics are essential for a country, a region or a continent to support economic activity and integration. In this sense, the availability and quality of statistics has greatly improved in Africa with the implementation of socio-economic surveys and population and housing census rounds and the implementation of initiatives and strategies for the development of statistics despite criticisms. These results are based on an important factor which is the availability of qualified personnel trained according to the appropriate standards for the production of statistics within national statistical institutes and more generally within National Statistical Systems (NSS). Training centres and institutes have developed since the 1960 s and have evolved to meet the training challenges.

However, the quality and continuously improvement of official statistics in Africa remains a matter of debate, and one that feeds into the issue of the continent's economic development and international cooperation in this area. These debates led to a better integration of national and international agendas for the develop- ment of statistics, in particular from the development of Poverty Reduction Strategy Papers (PRSPs) initiated by the World Bank.

In his article "Africa's Statistical Tragedy", Devarajan [1], World Bank Chief Economist, painted a bleak picture of statistics in Africa by pointing to a lack of capacity within African statistical institutions, unclear governance of responsibilities and a lack of stable funding by states. Responsibilities are certainly shared between States in crisis in unstable socio-political contexts and partners practices who have often destabilised the current activities of statistical apparatuses by mobilising production capacities for their own needs. Thus, expectations of public statistics in Africa could be excessive, given the complexity of the work and the organisations required by National Statistical Institutes (NSIs) to meet the growing needs of international agendas, while at the same time producing for current activities for domestic political priorities. There is a need to reconcile these two international and national demands as suggested by Deverajan's diagnosis that proposes the replacement of structural adjustments by PRSPs.

Faced with this observation, there has been a reappropriation of the strategic management of statistics in 
Africa to reverse the trend. The statistical function was repositioned at the regional level with the creation of the African Centre for Statistics established in 2006 within the United Nations Economic Commission for Africa (UNECA) [2], the creation of Statistical Commission for Africa (2006) (Stat-Com Africa), the organisation of concerted activities between the ECA, Africa Development Bank (AfDB) and Africa Union Commission (AUC). These actions have been reinforced with the definition of the Harmonised Strategy for Statistics in Africa (SHaSA) in 2010 and renewed recently in 2017 [3], the African Charter on Statistics (2009) and more recently the creation of the Pan-African Institute of Statistics (Statafric) 2017.

This renewal at the continental level can be seen as a consequence or culmination of a prior process of renewal and development of statistics at national level combined with a generational change all supported by the 1990 Addis Ababa Plan of Action (AAPA) for Statistical Development [4]. In this sense, the first meeting of the Statistical Commission for Africa [5] recognizes the contribution of generational change through five names: Mr. Julien Amegandjin, Mr. Oladejo Ajayi, Mr. Kweku deGraft-Johnson, Mr. Lamine Diop and Mr. Pali Lehohla.

In addition to the AAPA, The Marrakech Action Plan for Statistics (MAPS) was instrumental in being the basis of action plans for the development of statistics with the aim of producing better data for better results. This plan highlighted the interdependence between improving national and international statistical capacities. "Improvements in national statistical systems will lead to improved international statistics, while a more effective international system could provide more consistent advice and better support for improving national statistics" [6].

There have also been initiatives in the area of training for improvement in statistics. The link between statistical training and the need for quality statistics for development is clear. The African Group on Statistical Training and Human Resources (AGROST) was set up in 2010 under the aegis of StatCom by the main institutions involved in statistical system development in Africa with the main mission of coordinating activities and incentives within the framework of training and human resource development in Africa. The group has been leading various initiatives for harmonising training and coordinating training centres on the continent, particularly with regard to regional training centres in official statistics.

This article aims to outline the current situation of training in official statistics as well as the challenges to be met. To do this, the methodology combines a literature review and an internet research analysis of training centres in Africa. The field covered is about all types of training in schools or institutes, whether university or not, leading to a profession of statistician, demographer or specialisation in statistics. It shows that training centres have evolved over time in line with the history of the infrastructure construction and a statistical function in states and the place given to data in decision-making. Their current situation and the programmes offered take into account the changing statistical environment and technological developments. The programmes offered differ somewhat between language areas, although all centres are involved in the continental harmonisation initiative. It is essential that the training of statisticians is strategically designed so that they can be responsive and proactive in the face of changes and upheavals they will be confronted with in the context of data revolution and big data. Their training should reinforce the statistical literacy dimension with a view to reduce the gap between producers and users.

In addition to the introduction and conclusion, the article is organised in 5 sections. The first session presents the methodological approach and is followed by the section presenting the historical development of training centres and institutes. The third section deals with the current situation of training centres and institutes, distinguishing between categories and systems of training, offering a comparative analysis and topics covered. The fourth session outlines the specific situations of the regional reference centres of the English and French speaking systems. The last section is devoted to challenges and perspectives.

\section{Methodological approach}

This analysis of the state of official statistical training institutions adopts a descriptive and qualitative approach. A literature review of the topic is complemented by a web-based analysis of training institutions in Africa. The scope of the study covers all training in schools or institutes, whether university or nonuniversity, leading to a career as a statistician, demographer or specialisation in statistics. Internet research and personal knowledge of the sector have made it possible to build up a database of curricula and identify new training centres. Certainly not exhaustively (taking into account a broad definition of a statistician training centre), there are 300 programmes in about 100 training centres. The GIST identifies 10 regional training centres 
in official statistics in Africa. The analysis gives them a specific approach to case presentation.

The analysis constructs a typology of statistical training programmes that is used to rank and compare centres. The typology takes into account the education level and the nature of the degree delivered. Training centres are distinguished by university or non-university status, national or regional vocation. Programmes are organised according to three types: university training, engineer training and intermediate level vocational training.

\section{Training in official statistics in Africa: A response to the states development needs}

The organisation of training in official statistics is strongly correlated with the history of the infrastructure construction and a statistical function in the states as well as the place given to data in decision making. In this context Pali Lehohla [7] organises the temporal evolution into three main phases. The first phase is that of the construction of states after independence; the second phase deals with the political and economic crises suffered by the states; the third phase is presented as that of the awakening with important achievements backed by the construction and implementation of state development strategies, in particular statistical development strategies in the context of the United Nations.

Training institutions were built to meet the need to train statisticians for the production and analysis of official statistics. After independence, African states established few regional training centres for official statistics with the mission of training statisticians to compile administrative data and produce quantitative data needed for development plans. A significant number of statisticians have been trained in this way from relatively similar programmes across language areas. Most of these statisticians could not be retained by the official statistical system of these young nations, which after independence faced economic and political crises that severely disrupted the training and recruitment of statisticians into the national statistical system. Some regional training centres have been formed. With the revival over the last twenty years and the centrality of statistics and evidence-based policy and decisionmaking, the training of statisticians has regained interest. New regional centres have been established, training centres have been created in countries and some statistical institutes have created training departments within them.

Thus, despite the debates on statistics quality in Africa and the sometimes difficult context, statistical training institutes and centres have maintained their efforts and improved the training of highly qualified statisticians adapted to the needs of national statistical systems.

\subsection{Need for training centres creation}

The evolution of official statistics training institutions and centres has mirrored the establishment of statistical directorates and then institutes in countries. Most statistical training institutes and centres started as departments or directorates within the newly established statistical offices or directorates after the independence years. Their main role was staff training for planning purposes in response to the needs of statistical offices or directorates.

This is the case, for example, for the French-speaking countries, of ENSEA in Abidjan, whose predecessor was created in 1961 as a directorate of the statistics office and which received trainees and civil servants from French-speaking countries for training. From the outset, the school had a regional vocation. On the Englishspeaking side, one can cite for example the Institute of Statistics and Applied Economics (ISAE) at Makerere University in Kampala [8] which was established on 1969 as a regional centre for the training of Englishspeaking statisticians.

Indeed, between the 1960s and 1970s, various training centres for middle statistical executives were created following the recommendations of the African statisticians' second conference held in 1961 [9]. On the one hand, there were the French-speaking centres, which were:

- Institut Africain et Mauricien de Statistique et d'Economie Appliquée, IAMSEA (African and Mauritian Institute of Statistics and Applied Economics) in Kigali created in 1975,

- Centre Européen de Formation des StatisticiensEconomistes des Pays en Développement, CESD (European Centre for the Training of Statisticians and Economists from Developing Countries) in Paris establised in 1962,

- Institut National de Statistique et d'Economie Appliquée, INSEA (National Institute of Statistics and Applied Economics) in Rabat on 1961,

- Centre de Formation Statistique, CFS (Statistical Training Centre) in Yaoundé establised in 1961 which became ISSEA (Institut Sous-Régional de Statistique et d'Economie Appliquée) in 1984,

- École d'application de la Direction de la Statistique et des Études économiques establised in 1961 which became Ecole Nationale Supérieure 
de statistique et d'Economie Appliquée, ENSEA (Training Institute of Statistics and Applied Economics) in Abidjan,

- L'Institut des techniques de planification (ITP) (Institute of Planning Techniques) establised in 1970, in Algeria which became ENSSEA (Ecole Nationale Supérieure en Statistique et en Economie Appliquée) in 2008,

- Institut de Formation et de Recherche Démographiques, IFORD (Institute for Demographic Training and Research) in Yaoundé established in 1971 and

- Collège Statistique de Dakar, CS (Statistical College) in Dakar,

CESD has played a centralizing and catalysing role in French-speaking statistical training. Created in 1962, with the support of INSEE and the European Economic Community, (now European Union), CESD's mission was to ensure the quality of training for professional statisticians and economists from Frenchspeaking African countries, organise common entrance examinations for African schools of statistics and finance scholarships for students $[10,11]$. The recruitment of students in African schools was done on the basis of common entrance examinations and harmonised programmes meeting the statistical needs of countries. In addition, the regional training of statisticians of various nationalities guaranteed a community of practice based on a basis for integration through common statistical methodology.

On the English-speaking side, most of the regional (EASTC, ISAE, ISSER) and national centres were established between 1961 and 1970s in line with the recommendations of the African statisticians' second conference held in 1961. These are among others (cf. Woodward et al. (1997) [12]:

- Eastern Africa Statistical Training Centre (EASTC) founded on 1965 in Dar-es Salaam,

- Institute of Statistics and Applied Economics (ISAE) at Makerere University in Kampala,

- Department of Statistics at University of Ibadan, Nigeria,

- Department of Statistics and Institute of Statistical, Social and Economic Research (ISSER) at University of Ghana in Legon,

- Department of Statistics at University of Botswana in Gaborone,

- Department of Statistics at University of Dar-es Salaam in Tanzania,

- Department of Statistics at the National University of Lesotho, Maseru,
- Department of Statistics at the University of Addis Ababa in Ethiopia and

- Department of Statistics at the University of Swaziland.

Some of these centres were subsequently supported by the Statistical Training Program for Africa (STPA) from 1978 onwards to fill the gap of qualified statisticians in national statistical apparatuses.

The Statistical Training Programme for Africa (STPA) was established with the aim of training sufficient numbers of quality statisticians for African countries to handle the statistics needed for economic and social development. Its ultimate goal was therefore to ensure a permanent supply of qualified statistical staff for both public and private statistical offices and for governments through ministerial departments. The participating institutions worked on a coordinated basis with harmonised programmes tailored to the practical needs of governments, public and private sector.

STPA's as well as CESD's support consisted of curricula preparation, trainers' training, provision of shortterm visiting professors, provision of teaching materials, and the training of qualified African statisticians for statistical offices, even though most of them didn't pursue a career in the said offices because of the unattractive and uncompetitive salaries offered (by National Statistical Offices (NSOs)). Supports for statistical training were of course from different sources and multifaceted. The STPA and the CESD were not the only main supports. First there are the African governments, then the multilateral and bilateral partners (World Bank, European Union through COMSTAT 1 and 2, France, UK, etc.)

At the end of the STPA programme [13], in addition to the existing centres in English-speaking countries, many other university departments of statistics in several countries were established as training centres for statistical staff. For example, many Nigerian universities have established departments of statistics or mathematics that currently teach the subject. A similar situation has occurred in Kenya, Tanzania and Uganda. For French-speaking countries, this type of training is more likely to be provided by schools modelled on the French "Grandes Ecoles" (Top Schools of tertiary education). Some of the latter have been attached to universities, such as Top Schools in Tunisia and Morocco.

\subsection{Context and evolution factors}

The evolution of training centres for official statistics has been influenced by the priorities given to offi- 
cial statistics in states management, but also at regional and global levels. As with the history of the construction of statistical infrastructures, training programmes in official statistics experienced a boom period in the 1960s until the beginning of the 1980s economic crisis. This was followed by a sluggish period in the years of structural adjustment and then a new dynamic in the 21 st century with the multiplication of development programmes and objectives.

The need for well-trained statisticians for quality statistics production and analysis led to the definition of training and capacity building programmes in the early 1960s. It was during this period that most regional centres were established. Indeed, the United Nations assisted in the establishment of regional training programmes for statisticians. These regional programmes were well spread across the continent and language areas. There was harmonisation of middle executives training, which was done according to the programme defined by the recommendations of the African Statisticians Conference [9].

After the turbulent periods of structural adjustment and political crises that destabilised some statistical institutes and the statistical function within countries, a new dynamic has emerged over the last almost 20 years [14]. Various factors have influenced the revival of statistics in African countries and hence the training centres for official statistics. The Addis Ababa Plan of Action for the Development of Statistics in 1990 is the first of these $[4,16]$. This plan laid the foundation for the later national statistical development strategies which reinforced the training need of highly qualified statisticians and the need to strengthen and create new regional statistical training centres. The Marrakech Action Plan for Statistics (MAPS) established in 2004 was instrumental in being the basis of action plans for the development of statistics with the aim of producing better data for better results. This plan highlighted the interdependence between improving national and international statistical capacities [14].

After the stability found in almost all African countries and the need for better data for better results, as well as the need for democracy, as recalled by Pali Lehohla [7], there are a series of initiatives that will shape the statistical training evolution and place statistics at the heart of development. These include the establishment of the Paris21 consortium founded in 1999, the promotion of the General Data Dissemination Standards (GDDS) launched in December 1997 by IMF as well as the accompanying Data Quality Assessment Framework (DQAF) [17]; the preparation and imple- mentation of the International Comparison Programme (ICP) [18], the promotion of National Strategies for the Development of Statistics (NSDS), the Paris21 flagship, the African Statistical Development Symposium (ASSD), the Marrakech Plan of Action for Statistics in 2004, the African Forum for Statistical Development (FASDEV), StatCom Africa and the Strategy for the Harmonisation of Statistics (SHASA) in 2010 renewed in 2017. These initiatives have been complemented by the strengthening of strong statistical functions within regional institutions such as the AfDB, UNECA, the African Union Commission and the creation of regional centres such as Afristat or Statafric established in 1996 and 2017, respectively.

The GDDSs has been an important support for statistical capacity building of countries. It is an instrument that have recommended and prescribed practices with regard to coverage, periodicity, and timeliness for the dissemination of various macroeconomic data categories. GDDS was quickly adopted in Africa with a strong growth of countries participating in the initiative between 2001 and 2003 [17]. The renewal of statistical capacity building has benefited from the GDDS initiative and other initiatives that have followed for the African continent. Enoch and Kibuka [17] gives a non-exhaustive list. These initiatives have helped to integrate, to some extent, the priorities of developing countries and those of development partners with an emphasis on capacity building while avoiding duplication and promoting mainstreaming of statistics and monitoring in national development strategies.

The Paris 21 initiative has played a crucial role in the revival of statistics in Africa by filling a gap. It has created the conditions for the statistical systems renewal. It set up an advocacy for the promotion of the UN's fundamental principles of official statistics essential for quality statistics and policy making. Reflecting the international community's new impetus for statistical development, it has been a central player in the widespread adoption of "National Strategy for the Development of Statistics" (NSDS) documents in developing countries [19]. NSDSs have helped to formulate the needs for training statisticians at the country level and to address the issue of funding. These strategies have also led to the definition of strategies for the creation of training centres for executive statisticians at the country level in a twofold process: through local training centres created under the aegis of existing regional centres, through centres within statistical institutes for the continuing training of executives.

The training evolution and training centres and institutes in official statistics has also been influenced not 
only by the reappropriation of the strategic management of statistics in Africa through the African Charter on Statistics, SHASA and NSDS, but also by international agendas for managing development policies. These include the Millennium Development Goals (MDGs), which have been succeeded by the Sustainable Development Goals (SDGs). To these can be added international poverty reduction strategies [20], the rise of the evidence-based policy paradigm [21], results-based management which leads aid agencies to place statistical measurement at the heart of monitoring and evaluation of official development assistance [22], and the call for data revolution [23]. As mentioned above, NSDS by its complementariness with GDDS has allowed better management of both sets of international and national statistical agenda. NSDS encompasses statistical development issues with emphasis on infrastructure (office buildings, information technology systems, etc.), surveys and census, administrative data and information, training, etc.

A final initiative that has influenced the statistical training evolution in Africa is the C4D2 Initiative, particularly through its C4D2 Training component. Indeed, in 2017, the World Bank's Centre for Development Data (C4D2) established a partnership of like-minded institutions to improve and harmonise regional statistical training centres programmes (RSTCs) in sub-Saharan Africa, facilitating the adoption of global standards and best practices in household survey design, creating a network of household survey experts at the regional level, and promoting harmonisation across countries. The following African institutions are participating: the African Centre for Statistics (ACS) of the United Nations Economic Commission for Africa, the Eastern African Statistical Training Centre (EASTC) in Dar es Salaam, the Ecole Nationale Supérieure de Statistique et d'Economie Appliquée (ENSEA) in Abidjan, the School of Statistics and Planning (SSP) of Makerere University in Kampala, Uganda, and the Institut de Formation et de Recherche Démographiques (IFORD) in Yaoundé, Cameroon.) The initiative is in collaboration with the African Group on Statistical Training and $\mathrm{Hu}-$ man Resources (AGROST).

All these factors have influenced the evolution of training programmes and statistical training centres in Africa. To follow the principles of the data revolution and the African Charter on Statistics and SHASA [24], especially with regard to harmonisation, the official statistics training centres are participating in the AGROST working group.

The African Group on Statistical Training and $\mathrm{Hu}-$ man Resources (AGROST) was established in 2010 under the aegis of StatCom by the main institutions involved in statistical system development in Africa with the main mission of ensuring the coordination of activities and incentives within the framework of the training and human resources development in Africa.

The call for data revolution calls for the mobilisation of technological innovation and financial resources for statistics in a partnership framework for harmonisation of principles and standards, sharing of technologies and innovations, increased resources, inclusive governance and a pragmatic approach to the SDGs.

\section{Situation of statistical training institutions}

This section presents the categories of statistical training institutions by making a comparative analysis according to the categories and topics covered in curricula. It highlights the fundamental differences between language areas and topics covered.

\subsection{Categories of institutions}

Statistics Degrees do not have the same structures and nomenclatures. In particular, there is a difference according to the language border but also legal/ administrative systems. A distinction is made between the Anglophone system and the Francophone system. The Arabic-speaking system is divided between the two previous systems. The Portuguese system is quite close the francophone system.

\subsubsection{The Anglophone educational system}

In countries with an Anglophone university tradition, the Bachelor's degree is the degree awarded at the end of the first university cycle (undergraduate), after 3 or 4 years of study, depending on the country and the institution. A distinction is made between the Bachelor of Sciences (B.Sc.) and the Bachelor of Arts (B.A). The Doctorate of Philosophy (Ph.D) is the highest academic degree conferred by a university on students who have completed at least three years of study after a Master's degree before defending a thesis. Access to the first cycle of university studies depends on the marks obtained in the secondary school final year examinations (A-level).

Some statistical training centres also offer a Postgraduate Diploma in statistics. This training programme is normally completed in one year after obtaining a Bachelor's degree. It is a programme for students who want to improve their professional skills for the labour 
market. It is less demanding than the Master's degree and focuses on more practical applications.

The training programmes (Bachelor's programme) offered by statistical training centres are not always primarily devoted to statistics. Often, there are "hybrid" programmes that combine statistics with another discipline: economics, demography, sociology, business, computer science, etc. Students then obtain a "combined degree", which refers to the study of two subjects: a major subject and a minor subject, or a "joint degree", which refers to the study of two subjects in equal parts.

Statistical training centres in English-speaking countries are essentially university departments of statistics, EASTC being the exception. Exceptionally, they are schools or institutes attached to a university, such as the School of Statistics and Planning (SSP), formerly known as the Institute of Statistics and Applied Economics (ISAE), which is attached to Makerere University, or the Regional Institute for Population Studies (RIPS), which is attached to the University of Ghana.

\subsubsection{The francophone educational system}

Training in official statistics is provided in schools and training centres which are entities independent of universities in the French-speaking system. The courses in these training centres are designed in the image of the French model based on the system of "Grandes Ecoles". Diplomas are specific and bear the names: Agent des Travaux statistiques, AT (Statistical Officer Diploma), Adjoint des travaux statistiques, AD (Assistant Senior Statistician Diploma), Statistician Analyst (AS), Ingénieur des Travaux Statistique, ITS (Statistical Engineer), Ingénieur Statisticien Economiste, ISE (Statistician Economist Engineer).

ATs are intended for the supervision of collection operations. As for ADs, their primary vocation is the production of current statistics as well as the supervision of collection operations, initial processing and analysis, as well as the dissemination of statistical information. ITS are professional statisticians whose training gives them excellent skills in the production, processing, analysis and dissemination of statistical information. The ISE training gives graduates their vocation of research, design, organization and development of the statistical production of public and private structures. They develop strong skills for economic, financial or sectorial analysis.

In 2007 , for the sake of clarity and to ensure the mobility of their graduates towards the university system, the training schools started a process allowing their diploma to correspond with the Bologna Process.
After the Bologna Process [25], countries with a francophone university tradition adopted the "LMD" system: Licence, Master, Doctorat (Bachelor, Master, Doctorate) which organises the higher education system into three levels: Licence (3 years); Master (5 years); Doctorate (8 years) with a system of capitalisable and transferable credits.

Statistics training programmes in universities are mainly found in the Departments of Mathematics and Computer Science. In general, they are mainly mathematics degrees, with the specialisation level in statistics varying considerably from one programme to another. In undergraduate programmes, the statistics option is often only offered in the third year of the Licence after a two-year core curriculum in mathematics. However, some professional Licences offer a complete course in statistics with more applied training. At the Master level, there are mainly research Masters that offer a specialisation in probability and statistics after a Licence in Mathematics (with or without a statistics option). Some Master programmes are more applied, usually in biostatistics. Very few university programmes are therefore oriented towards public statistics or economic and social statistics in general.

It should be noted, however, that all the institutes that offer training programmes in demography are academically attached to universities and award university degrees. This is the case of IFORD (Institut de Formation et de Recherche Démographique) which offers a professional Master's degree in demography, CEFORP (Centre de Formation et de Recherche en matière de Population) in Benin which offers a Master's degree in Population and Urban Dynamics and ISSP (Institut Supérieur des Sciences de la Population) in Burkina Faso which offers a professional Licence in social statistics and a Master's degree in population sciences with professional and research options.

\subsection{Specific degrees of francophone regional schools}

In contrast to universities, training centres or institutes in public statistics award degrees modelled on the French "Grandes Ecoles" (Top Schools) system and are distinguished by a very selective entrance examination and small numbers of students. They award Engineer Degrees and Advanced Technician Diplomas in statistics. While the structure of the Advanced Technician Diplomas is almost identical between language areas, Engineer Diplomas are very specific to French-speaking areas.

In sub-Saharan Africa, ENSEA (Ecole Nationale Supérieure de Statistique et d'Economie Appliquée) 
in Côte d'Ivoire, ISSEA (Institut Sous-Régional de Statistique et d'Economie Appliquée) in Cameroon and ENSAE (Ecole Nationale de la Statistique et de l'Analyse Economique) in Senegal form a network, Réseau des Ecoles de Statistique Africaines (RESA) (African Schools of Statistics Network), with a common competitive entrance examination organised at the level of all French-speaking countries and a relatively high degree of harmonisation of their programme. These three schools offer a three-year Engineer Degree in Statistics and Economics (ISE, 'Statistician-Economist Engineer') course after a competitive entrance examination open to students of preparatory classes (in countries where this exists) and to holders of a Licence (Bachelor's degree) in mathematics or economics. The Engineer Degree in Statistics and Economics (ISE) awarded by these schools therefore sanction, depending on the case, 5 or 6 years of study after the Baccalauréat (High School final year/A-level equivalent diploma). The training organisation is similar in the three schools. The curricula are identical for the first two years. The first year is largely devoted to homogenising the knowledge of students from different backgrounds (mathematics and economics). In the third year, each school differentiates itself by offering specialised advanced courses in form of options.

In North Africa, INSEA (Institut National de Statistique et d'Economie Appliquée) in Morocco, ESSAI (Ecole Supérieure de Statistique et d'Analyse de l'Information) in Tunisia and ENSSEA (Ecole Supérieure de la Statistique et d'Economie Appliquée) in Algeria, issue the title of State Engineer corresponding to the Baccalauréat +5 level (High School final year/A-level equivalent Diploma +5 years of higher studies). INSEA's State Engineer Degree is awarded after three years of training, with access to the first year mainly after two years of preparatory classes integrated in Professional College. ESSAI delivers the National Engineer Degree in Statistics and Information Analysis. ESSAI training lasts three years after two years of preparatory classes. ENSSEA is distinguished from other schools by its post-Baccalauréat recruitment (the classification is based on the general average obtained at the Baccalauréat (High School final/A-level) exam and a 5-year training course leading to the State Engineer Degree in Statistics and Planning.

\subsection{Relatively common degrees in language areas}

\subsubsection{Master's degree in public statistics}

In addition to Engineer graduates, RESA's regional schools offer Master's degrees in public statistics and data science. Curricula are built and nurtured by practice and research in the field. For example, the Master's degree in Public Statistics common to RESA schools was built under the aegis of AGROST from research and technical assistance within countries of the agricultural and rural statistics development programme (the global strategy): data science and actuarial science for instance.

\subsubsection{Intermediate level degrees}

In contrast to the higher levels, the training centres or institutes in the English-speaking and French-speaking systems offer relatively similar intermediate level degrees. This appears to be a result of the middle executives training programme set up under the aegis of the United Nations in the 1970s, the STPA.

Indeed, statistical training centres also offer middlelevel vocational training. These short vocational courses (from 1 to 2 or even 3 years) are sanctioned by diplomas or certificates that do not always allow for further university studies. For the most part, these programmes are those that were accepted under the Statistical Training Programme for Africa (STPA) [13,26] implemented by the ECA in the 1980s. These diplomas are awarded by the schools that also train engineers.

In English-speaking countries, these short professional courses are called Certificate in statistics (1 year) or Diploma in statistics (2 years). In French-speaking countries, these professional courses are called Agents des Travaux statistiques, AT (Statistical Officer) for the one-year course after a Baccalauréat (High School final year/A-level equivalent diploma) in science or Adjoint des Travaux statistiques, (Assistant Senior Statistician) or Technicien Supérieur de la statistique, TSS (Advanced Technician in Statistics) for the two-year course after recruitment by entrance examination among holders of a Baccalauréat (High School final year/A-level equivalent diploma) in science.

In the Arabic-speaking countries, Algeria, Tunisia and Egypt, these same training types exist with relatively different names but a quite similar structure inherited from the STPA programme. Morocco has stopped training Advanced Technicians in statistics.

\subsection{Comparative analysis}

Statistical training programmes have some concordance or particularities, especially with regard to university degrees. Indeed, while there are a certain number of identity factors common to all engineer courses and a certain accordance between intermediate professional 
Table 1

Differentiation between types of curricula in statistics

\begin{tabular}{|c|c|c|c|}
\hline Characteristics & Engineer degrees & University degrees & Diploma, professional certificates \\
\hline Vision/Mission & $\begin{array}{l}\text { Statistical experts who combine scientific } \\
\text { rigour with practical problem-solving } \\
\text { skills }\end{array}$ & $\begin{array}{l}\text { High-level specialists and researchers } \\
\text { with a good command of statistical } \\
\text { processing and modelling tools (Varies } \\
\text { according to the academic traditions of } \\
\text { the institution) }\end{array}$ & $\begin{array}{l}\text { Technicians able to assist senior } \\
\text { statistical staff and collaborate with } \\
\text { specialists in other disciplines }\end{array}$ \\
\hline Fields of study & $\begin{array}{l}\text { Similar: Applied statistics with a strong } \\
\text { economic bias }\end{array}$ & $\begin{array}{l}\text { Diversified: Theoretical statistics, } \\
\text { Applied statistics, Demography } \\
\text { Actuarial science, Bio-statistics }\end{array}$ & $\begin{array}{l}\text { Similar: Basic statistics, data collection } \\
\text { methods for official statistics }\end{array}$ \\
\hline Admissions & Competitive entrance examination & $\begin{array}{l}\text { University entrance examination or } \\
\text { selective guidance system or selection } \\
\text { on the basis of applications }\end{array}$ & $\begin{array}{l}\text { Entrance examination or selection on the } \\
\text { basis of applications }\end{array}$ \\
\hline Length of study & 3 to 5 years (depending on entry level) & $\begin{array}{l}\text { Undergraduate: } 3 \text { or } 4 \text { years } \\
\text { Graduate: } 2 \text { years }\end{array}$ & 1 or 2 years \\
\hline $\begin{array}{l}\text { Curriculum/ } \\
\text { Pedagogical } \\
\text { approach }\end{array}$ & $\begin{array}{l}\text { Vocational training focused on design ac- } \\
\text { tivities } \\
\text { Contains a solid foundation in mathemat- } \\
\text { ics and computer science, in-depth knowl- } \\
\text { edge of quantitative methods and economic } \\
\text { analysis } \\
\text { Pedagogy focused on personal skills (com- } \\
\text { munication, group work) } \\
\text { Professional experience is integrated in the } \\
\text { curriculum through internships, field } \\
\text { surveys, projects and seminars delivered } \\
\text { by professionals }\end{array}$ & $\begin{array}{l}\text { Academic training focused on the mas- } \\
\text { tery of the subject field } \\
\text { Priority is given to the acquisition of } \\
\text { scientific and technical knowledge } \\
\text { rather than the development of cross- } \\
\text { curricular skills } \\
\text { Organization and methods of official } \\
\text { statistics more or less ignored } \\
\text { Greater variety of choices in the } \\
\text { English-speaking system (insofar as a } \\
\text { significant fraction of the curriculum is } \\
\text { elective) } \\
\text { and more practical training, learning by } \\
\text { problems and projects developed }\end{array}$ & $\begin{array}{l}\text { Training focused on the development of } \\
\text { intermediate professional skills } \\
\text { Emphasis on the acquisition of basic } \\
\text { knowledge in mathematics and statistics } \\
\text { Very practical computer training with a } \\
\text { focus on the use of statistical software } \\
\text { Emphasis on working methods in the } \\
\text { field of data collection } \\
\text { Teaching of openness and communica- } \\
\text { tion for the adaptation to the professional } \\
\text { environment } \\
\text { Practice of surveys and internships } \\
\text { included in the curriculum }\end{array}$ \\
\hline $\begin{array}{l}\text { Qualifications } \\
\text { obtained and } \\
\text { purpose }\end{array}$ & $\begin{array}{l}\text { Design of a statistical information collec- } \\
\text { tion and analysis project } \\
\text { Skills in economic analysis and decision- } \\
\text { making tools in the field of public policy } \\
\text { Ability to stand back and follow the evolu- } \\
\text { tion of techniques and methods } \\
\text { Mastery of project management and evalu- } \\
\text { ation } \\
\text { Ability to manage a work team } \\
\text { Ability to manage the implementation of a } \\
\text { survey }\end{array}$ & $\begin{array}{l}\text { Mastery of modelling techniques and } \\
\text { scientific data processing tools in the } \\
\text { context of a statistical study or research } \\
\text { project } \\
\text { Knowledge specific to the speciality, } \\
\text { e.g. bio-statistics, actuarial science, etc. } \\
\text { Ability to carry out research activities } \\
\text { in fundamental and applied statistics }\end{array}$ & $\begin{array}{l}\text { Good command of survey techniques } \\
\text { Ability to produce first analysis of graph- } \\
\text { ical and numerical summaries of data } \\
\text { Produce routine statistics and supervise } \\
\text { interviewers }\end{array}$ \\
\hline $\begin{array}{l}\text { Qualifications } \\
\text { of teaching } \\
\text { staff }\end{array}$ & $\begin{array}{l}\text { Scientific qualifications (doctorate) and } \\
\text { professional qualifications (significant part } \\
\text { of the teaching provided by working } \\
\text { professionals) }\end{array}$ & $\begin{array}{l}\text { Academic qualifications required to } \\
\text { teach at the University }\end{array}$ & $\begin{array}{l}\text { Academic and professional } \\
\text { qualifications }\end{array}$ \\
\hline Staff size & Reduced & Variable & Reduced \\
\hline $\begin{array}{l}\text { Main job } \\
\text { opportunities }\end{array}$ & $\begin{array}{l}\text { Positions of responsibility in public } \\
\text { statistics, large companies, financial } \\
\text { institutions and international organisations }\end{array}$ & $\begin{array}{l}\text { Research positions in the statistical de- } \\
\text { partments of large companies and ad- } \\
\text { ministrations, research units } \\
\text { Teaching }\end{array}$ & $\begin{array}{l}\text { Middle manager positions in official } \\
\text { statistics and other administrative } \\
\text { entities }\end{array}$ \\
\hline
\end{tabular}

Source: author.

courses, particularly in the general objective of the studies, it is very difficult, because of their great diversity, to identify the characteristics common to university-type programmes, for which the orientations may be very different according to the institutional or geographical context (See Table 1).

In French-speaking countries, statistics programmes in universities are generally concentrated in the Departments of Mathematics and Computer Science. Statistics is primarily seen as a sub-discipline of mathematics and teaching is almost exclusively focused on mathematics. The pedagogy revolves around the acquisition of knowledge in the field of the speciality and the opening disciplines are almost absent. Methods are classical: lectures, tutorials, practical work.

As for schools or training centres dedicated to the statisticians training, the statistical training courses are oriented in a completely different dimension from the 
university system. Engineer courses combine theory and practice and are oriented towards the professional world. Students are trained in multiple skills in their fields. The training in statistics is transversal to several more or less quantitative disciplines. The disciplines chosen give a robust character to the programme and ensure that the statistician has a greater possibility of adapting to the job market. The disciplines are mathematical, economic, demographic, computer science, statistical or related subjects with further specialised advanced courses to enable students to specialise in specific areas.

In the English-speaking system, statistical curricula are implemented by universities' statistical departments. They offer a greater variety of courses. This variety is facilitated by a greater flexibility in the choice of courses, a fraction of which is generally elective, and the presence of complete universities that allow interaction with other disciplinary fields and the setting up of "hybrid" programmes. On the other hand, the Training Centres clearly display a vision more oriented towards the acquisition of more practical skills as well as skills development that are crucial in a professional environment.

\subsection{Topics covered in curricula}

Topics covered in statistical training centres or institutes follow the pedagogical principles adapted to the fields. Thus, even if there are differences in curricula, there are efforts to harmonise them at the continental level. This is one of the main objectives of AGROST, the African Group on Statistical Training and Human Resources and GIST, the network of statistical training institutions.

Through the analysis of statistical training curricula, this section aims to identify the typical content of statistical curricula in African training centres. In this sense, the principle is to train practice-oriented statisticians. The teaching therefore favours a data-based and problem-oriented approach to learning.

There are four key aspects to a statistics curriculum:

- Theory: important for understanding developments in statistics and showing that statistics can be geared towards different directions. It allows the expert to step back and adapt to changing techniques. The teaching of theory should go beyond the subject matter and be conceived as learning how to model.

- Computer science or technology: this is an indispensable component of statistical training and helps to make theory more relevant. Computers have indeed made many modern statistical theories and methods possible because of the computational possibilities.

- Statistical reasoning and experience: more than a set of techniques, the teaching must bring a statistical thinking mode and involve students in solving concrete problems and make them acquire statistical experience through real-life situations.

- Soft skills: the training should not be limited to technical aspects but also cover management, explanation and dissemination of data. Communication skills are just as essential as knowledge of statistical methods for communication with both specialists and non-specialists.

The analysis of the subjects addressed in statistical training centres or institutes allows them to be organised into areas of concentration. There are nine areas of concentration:

- Statistical theory: The curriculum includes courses that focus mainly on statistical theory. Mathematics is very present. There are practically no practical applications. No science is taught apart from statistics (economics, demography, social sciences, biosciences ...) and general disciplines are more or less ignored.

- Statistics - computer science: The curriculum focuses as before on statistical theory with a strong computer science emphasis. It contains an important part of general computer science.

- Applied statistics (general applied statistics): The curriculum does not offer applications in one particular field but an introduction to applications in several different fields. It contains courses related to official statistics.

- Statistics - Economics: The curriculum focuses on economics, not only as an area of application but also as a field of study in its own right. This area of concentration also includes the few curricula that lead to specialised studies in business and management.

- Demography: This curriculum leads to a full training as a demographer or demographic statistician. It includes some specialised training in social statistics.

- Actuarial science - Finance: This curriculum is concerned with actuarial science, insurance, finance.

- Bio-statistics: This curriculum deals with Life Statistics (bio-statistics).

- Professional statistics: This curriculum leads to intermediate level professional training with a focus on official statistics. 
Table 2

Course classification in statistical training

\begin{tabular}{|c|c|}
\hline Mathematics: & Probabilities: \\
\hline Algebra & Combinatorial analysis \\
\hline Analysis optimization & Probability calculus \\
\hline Integral and differential calculus & Random variables \\
\hline Topology & Probability theory \\
\hline \multirow[t]{2}{*}{ Operational research } & Measurement theory \\
\hline & Stochastic processes \\
\hline Descriptive statistics I & Descriptive statistics II \\
\hline One and two dimensional descriptive statistics & (data analysis) Multivariate statistical methods \\
\hline Description of time series & (factorial methods, Classification methods...) \\
\hline Inferential Statistic: & Survey Methods/Surveys \\
\hline Sampling & Survey design and analysis \\
\hline Estimates & Organisation of a statistical survey \\
\hline Tests & Survey processing \\
\hline Nonparametric statistics & Survey theory and practice \\
\hline Bayesian statistics & Survey methodology and quality \\
\hline \multicolumn{2}{|l|}{ Decision theory } \\
\hline Statistical Modelling/Econometrics: & Computer science \\
\hline Regression & Computer environment \\
\hline Analysis of Variance & Operating systems \\
\hline Time Series Econometrics & Computer networks and the Internet \\
\hline Qualitative variables Econometrics & Algorithms and programming \\
\hline Panel Data Econometrics & Object-oriented design and programming \\
\hline Econometrics for Finance & Visual Basic \\
\hline Macro-Econometrics & Web programming \\
\hline Non-Parametric Econometrics & Statistical programming: SAS, R, Gauss ... \\
\hline Non-Linear Econometrics & Databases \\
\hline \multirow[t]{5}{*}{ Bootstrap Forecasting } & Information systems design \\
\hline & GIS, \\
\hline & Data-mining \\
\hline & Neural networks \\
\hline & Statistical software \\
\hline Official statistics & Economics - Business Management \\
\hline National accounts & Introduction to Economics \\
\hline Price statistics & Microeconomics \\
\hline Education statistics & Macroeconomics \\
\hline Health statistics & History of Economic Thought \\
\hline Labour and employment statistics & Game Theory \\
\hline Agricultural statistics & Economics of Uncertainty \\
\hline Business statistics & Public Economics \\
\hline Foreign trade statistics ... & International Economics \\
\hline \multirow[t]{8}{*}{ Organisation of the national statistical system } & Development Economics \\
\hline & Poverty Analysis \\
\hline & Monetary Economics \\
\hline & Business Analysis \\
\hline & Accounting \\
\hline & Business Management \\
\hline & Marketing \\
\hline & Risk Management \\
\hline Demography and social sciences & Life Statistics \& Actuarial Science, Finance \\
\hline \multirow[t]{5}{*}{ Project management - Monitoring and evaluation } & General education \& personal development \\
\hline & Communication \\
\hline & Expression techniques \\
\hline & Foreign languages \\
\hline & Research methodology \\
\hline
\end{tabular}

Source: author.

- Data science: The curriculum brings together computer science and statistical methods and applies to large amounts of generally unstructured data.
Training institutions in official statistics, in contrast to universities, best integrate all areas of concentration and in particular the concerns of official statistics such as "applied statistics", "statistics and economics", 
"occupational statistics", "demography". These courses cover economic and social statistics and provide real knowledge of the collection and analysis methods of official statistics.

Notwithstanding differences in content which may be due to specific needs or different levels of depth, courses in statistical training centres or institutes can be grouped according to the classification in Table 2.

By making a comparison based on the average annual hourly volumes and the relative weight of the various subjects in the types of programme, we obtain a categorisation of the courses. It can be seen that the number of classroom hours per year of study is greater in Engineer courses (635 hours on average) and in intermediate vocational courses (625 hours on average). The number of hours devoted to university-type courses remains well below the average of around 500 hours.

Engineer-level courses are also characterised by the importance given to economics and the importance of soft skills, including project management and evaluation. Vocational courses are characterised by a strong emphasis on general education, mathematics and IT. This is the type of training where official statistics, statistical methods and survey methods have a higher relative weight. Statistical modelling has a lower weight. Specialisations in areas such as project management, actuarial science or biostatistics are almost absent.

University programmes are characterised by a larger share of their curriculum devoted to mathematics, computer science, probability and stochastic processes. There is a concentration of these programmes on the disciplinary field. Official statistics, survey methods or personal development are almost not part of university programmes.

\section{Transformations in public statistics training centres or institutes}

This section presents the orientations, developments and current situation of training centres or institutes in public statistics, based on the specific cases of RESA schools which are ENSEA, ENSAE and ISSEA and on the case of EASTC in the English-speaking world.

As presented earlier, RESA, formalised by texts in 2016, is the network formed by three statistical training schools: ENSEA in Abidjan, Côte d'Ivoire; ENSAE in Dakar, Senegal; and ISSEA in Yaoundé, Cameroon. RESA is, through its activities, longevity and future projects, a successful experiment in regional integration in the statistical field of initial and continuing train- ing. The network's schools are open to all nationalities through the common competitive entrance examination organised in Africa and welcome students from all over the continent, regardless of the language area.

ENSEA is the oldest school in the network and its status has, until now, given it the necessary flexibility to try out experiments which were then deployed by the others (opening up to continuing training, language laboratory, opening up to non-French speaking students, Master's programme, technical expertise for external organisations, twinning with national schools, etc).

In response to the training needs of the National Statistical Institutions and the actions defined in the NSDS, ENSEA has established training conventions in official statistics with various countries and training centres. On the one hand, there are the training centres established under the direction of ENSEA and which carry out ENSEA middle executives curricula attested by ENSEA diplomas. These are the training school in Niamey in Niger, the statistics division of the Ecole Nationale des Régies Financières (Enaref) in Ouagadougou in Burkina Faso in 2004, the Institut National de la Formation Administrative (INFA) in Madagascar in 2006 and the training institute in Conakry in Guinea in 2018. On the other hand, there are training centres or institutes whose training cycles in official statistics have been developed with the cooperation of ENSEA for the establishment of curricula and trainers' training. These are: the University Institute of Technology in Djibouti, the Ecole d'Administration in Lomé, the Centre for Training and Development in Statistics in Bamako and three statistical training schools in the Democratic Republic of Congo.

Another response to the need for human resources in the NSS has been the creation of specific Masters in areas of application of official statistics: health, agriculture, education, environment, monitoring-evaluation, data science, etc. With a view to widening the pool of training available for statistical professions, these Masters are intended primarily for non-statisticians working in NSSs, particularly in ministerial departments. These Masters are built on material developed and tested at the international level, such as the Master in Agricultural Statistics set up under the aegis of the Global Strategy for the Development of Agricultural Statistics within the framework of AGROST.

Recently, under the leadership of ENSEA, RESA schools have carried out an educational renovation to take into account the global evolution of the statistical environment but also the technological evolutions in the data revolution context. Indeed, higher educa- 
tion at the international level has seen the harmonisation of the training output levels with the curricula and training offers organised according to the "LMD" reform of the Bologna process [25]. Similarly, the statistical sector is facing major upheavals and challenges: data revolution [22], data abundance, high diversity and greater variety of data sources, evidence-based policy paradigm [21], results-based management, development agendas requirements. All this requires new skills in the field.

In this context, the renovation has led to the opening of new courses and the reorganisation of training offers into four levels:

- The opening of a new Bachelor level "Analyste Statisticien”, AS (Statistics Analyst) course, whose students are recruited by African competitive entrance examination after a Baccalauréat (High School final year/A-level equivalent diploma) in science. This degree combines the skills required of middle managers and advanced technicians in statistics. It provides AS graduates with the statistical tools and methods of the modern statistician (of tomorrow).

- The development of Master's degrees focused on sectoral themes. A limited number of students are recruited through a competitive entrance examination combined with the valorisation of professional experience. It provides students who are already equipped with sectoral skills, new skills in applied statistics which are specific to their field.

- The Engineer degree which retains the name ISE with the same recruitment level set at the Licence level (Bachelor level) in economics or mathematics. Students are still recruited through a highly selective African competitive entrance examination. In addition to receiving training with solid scientific, technical and cross-cutting skills that are essential in a professional setting, ISE graduates receive training that emphasises practical experience with projects, internships, survey practices and the involvement of professionals in the training.

- The opening of a doctoral programme which allows the training of statisticians and economists with the required level of applied research in the field of statistics. The future Doctoral students have the opportunity to write theses in the field of statistical methods in response to the needs and concerns of national statistical institutes and more generally of the NSS, but also in the sectoral field of economics or applied statistics.
These programmes are organised in such a way as to best meet the needs of public statistics. Teaching methods combine new technologies and developments in statistical education. Teaching and learning activities are organised according to active pedagogical principles, cognitivism [27]. Students are put into situations with active methods: case studies, project work, simulations, use of technology, group work. The diversity of backgrounds is exploited to enhance students' social and personal development, critical and disruptive thinking. Technology is mobilised in the teaching and allows students to explore and analyse data by mobilising statistical intuition for the mastery of concepts and results interpretation.

To reach large audiences, hybrid teaching methods are mobilised with distance learning through the platforms development.

Distance learning platforms are also being developed in regional training centres such as EASTC, which receives nationals from English-speaking countries in its training courses. After the pilot phase, the system will be extended to all the centre's official statistics training programmes.

Currently the centre has two main programmes namely Official Statistics and Agricultural Statistics. Official Statistics is taught at Masters', Bachelors', Diploma and Certificate levels but Agricultural Statistics is taught at masters' level only. Enrolment in these two courses has been declining from year-to-year due to a decrease in the number of students from Centre's user countries.

To address this challenge, the Centre has introduced programmes that will increase enrolment at the same time serve as a feeder programme for Official Statistics and Agricultural Statistics. These new programs blend Statistics, ICT and Economics. Programmes include:

- Bachelor of Data Science and Information Technology. Data science breaks the gaps of working with data; it solves the problems traditional statistical methods fail to address. It provides skills and knowledge to managers, manipulates, extracts, and interprets knowledge from tremendous amount of data and of any type.

- Bachelor of Agricultural Statistics and Economics. Noting the demand for agricultural statistical experts, the Centre has introduced a Bachelor Degree programme of Agricultural Statistics and Economics aiming at producing highly knowledgeable, expertly skilled and creatively innovative statistical professionals to meet the demand of the agricultural sector. This course is therefore 
geared towards producing agricultural statisticians who will fit in the production of agricultural statistics, advising in their use as well as performing economic analysis for the sector.

- Bachelor of Business Statistics and Economics. The Centre has introduced the Bachelor of Economics and Business Statistics course aiming at producing highly knowledgeable, expertly skilled and creatively innovative professionals to meet the demand of the Business statistics and Economics market. The course is therefore geared towards producing Business Statisticians who will fit in any sector of the economy both in the production of Business Statistics and advising in their use.

- Certificate in Information Technology and Diploma in Information Technology. The course aims at providing the staff with programming, network management and database administration knowledge and skills that will help them to perform computer related activities within an organization. The course also aims to produce a highly qualified staff in data collection methods and data processing using computing devices like laptops, smart phones and tablets.

Methodological approaches to teaching are in line with questions raised by the GIST, which is organising the reflection through three working groups: Online gateway and e-learning community of practice; Statistical Literacy in the context of the 2030 Agenda; Addressing specific NSO demands. The Global Network of Institutions for Statistical Training (GIST) is a network of international and regional training institutions, working together to build sustainable statistical capacities through efficient, effective, and harmonized delivery of training at global and regional levels, that will enable production and use of quality data and statistics including monitoring and implementation of SDGs.

\section{Challenges and prospects for statistical training}

National Statistical Institutes heads were invited to express their needs within the framework of a data collection carried out for the educational renovation operation initiated by RESA schools. NSI managers revealed that they are looking for statisticians with a great deal of abstraction as well as a high level of practice, i.e. statisticians must be operational at the end of their training. To this end, as evidenced by the NSDS, they express a strong need and a significant increase in the proportion of their technician and executive statisticians from training schools. These profiles are directly operational and adapted to the Institute needs for the production, processing, analysis and dissemination of data according to the standards, principles and methodologies of public statistics. The other staff coming from universities have a major numerical deficiency and practical competence in official statistics. They have at best some knowledge of applied statistics but very little professional competence to work as statisticians in the NSIs.

The thematic needs sought by NSIs are related to the traditional subjects of official statistics and the usual missions of NSIs (economic and social analysis, survey and sectoral statistics, archiving and dissemination of data, etc.) and the states' current governance challenges in Africa and the international agendas monitoring, including the SDGs. There are also needs for mastery of statistical software, management and processing of big data as well as improved writing and communication skills.

The private sector, like the public sector, is expressing a growing need for statisticians due to the development of certain business sectors in Africa (banking, insurance, telephony) and the evolution of technologies that require increased management of almost automatically generated data.

Also, we can note with [28] that statistics in Africa cannot do without a real dialogue with statistics users and for producers to understand their needs and without capacity building on the side of the users, with particular emphasis on the analysis and dissemination of statistics to facilitate their use. Indeed, in the information age, society needs to be statistically literate not only in the workplace but also in everyday life. There is a gap to be filled in Africa in this area.

With the data revolution and the increased need for official statistics, official statistics is in the midst of major upheavals with important challenges to be met in the face of major changes. On the one hand, there is a growing demand for reliable and transparent figures in all economic and social fields, which increases the need for statisticians or data scientists. They need to be able to conceptualise the data specific to each field and render them in a way that is readable by decision-makers and the general public. On the other hand, with the data revolution, the production of economic and social statistics is no longer the exclusive preserve of states. NSIs have to rely on other resources than the often costly and delicate field surveys to analyse the economic and social situation of the country. These new massive and open data sources require people capable of assessing systematic biases to process them correctly. Also with 
the new data sources, the proliferation of databases and the capacity of NGOs or universities to produce field surveys in key social sectors (health, education, justice) in particular with randomised evaluations [22], there is a need for specialists able to validate these methodologies and results obtained. The need for highly trained public statisticians is thus likely to increase further in the coming years.

The evolution of the official statistics ecosystem and related challenges raise the question of the statistician of tomorrow or the training centre of the future. Training in official statistics remains a major challenge to which training centres must respond both in quantity and quality. There is a need to maintain a strategic watch and to adapt the training model. It is essential that the training of statisticians is strategically thought out so that they can be reactive and dynamic in the face of changes and upheavals they will have to deal with. The educational renovation carried out by RESA schools, with harmonised curricula at the Engineer level and an opening up to the Doctorate programme, is geared towards meeting the challenges posed here. This is an approach that should be consolidated at the level of AGROST beyond the geographical sphere, administrative, legal and the language barrier. More generally, within a framework of consultation and harmonisation, this approach and responses to be provided should be taken up at the level of GIST, the global network of training centres in statistics. This forward strategic watch for training that meets the needs of NSSs cannot be done without funding and the establishment of a strategic partnership between NSIs and training centres, between training centres and professional partners or simply between all strategic players. The issue of the quality of official statistics is not only a question of training, but of financial resources dedicated to statistics, of governance of the official statistical systems, etc. Upskilling needs to become an essential part of statistical planning.

\section{Conclusion}

With the concept of data revolution, big data, the need to inform decisions with evidence as well as the need to produce indicators in the context of international agendas such as the UN 2030 Agenda and the African Union 2063 Agenda, official statistics are undergoing upheaval, specific expectations and new needs. This raises challenges regarding the training of the statistician of the future, the model and the type of training institute for the official statistician.
Indeed, the need for statisticians and data professionals is growing due to the increasing demand for reliable and transparent statistics in all economic and social fields, and the production of data at local, regional, national and international levels by various organisations. The statistician must be able to conceptualise, collect and analyse data with the appropriate tools in the context of technological change. With new sources of structured and unstructured data such as mobile data, satellite data, internet data, etc., he/she should be able to process them properly, assess systematic biases, reliability for timely produced official statistics and inform the user-producer dialogue for reliable economic and social policies.

In this context, we have analysed and presented in this paper the situation of training in official statistics in Africa. We have shown that training curricula and the training centres and institutes situation has evolved historically with the statistical infrastructure. There have been three main periods, that of planning in newly independent states building the statistical infrastructure, that of states in crisis with brain drain and destruction of the statistical infrastructure, and the flourishing period of the resolute commitment of Africans in strategic steering, rebuilding of the statistical infrastructure in a context of data revolution and technological change.

Degrees, organisation and structuring of training are quite different according to the language area. There is a real diversity in the training content and strategies. In the French-speaking countries, training of professional statisticians is mainly provided by specialised institutions, both at the Engineer and the Advanced Technician level. This training combines the development of scientific and technical skills as well as crosscutting skills that are essential in a professional context. A great deal of weight is given to practical activities through projects, internships, survey practice and the involvement of professionals in teaching. In contrast to specialised training institutions, statistics programmes in universities are mainly located in mathematics departments and focus on the mastery of the discipline, neglecting opening disciplines and professional skills development.

In English-speaking countries, the training model is deliberately university-based. There is intermediate vocational training in both regional centres and universities. Courses offer a combination of theory and practice with the aim of producing statisticians who can provide professional service. Curricula offer a wider variety of study specialisation.

There have been efforts to harmonise programmes and curricula. Under the aegis of Agrost, the training 
centres or schools adopted a harmonised curriculum for intermediate level vocational training. This was made easier by the fact that these programmes were based on the STPA. The "Engineer in Statistics" training type should be a model for non-French speaking countries in order to diversify and professionalise. Indeed, the ESA model, international schools with coordinated programmes adapted to the current realities of data science and ensuring the training of public statistics executives, can be considered especially favourable to meeting the requirements of the future.

The demand for statisticians and more generally for highly qualified data professionals is pressing in all sectors, in the private as well as the public sector. The training of statisticians, particularly in Africa, is a major challenge. Training must be developed and carried out at the highest level of competence. In addition to traditional skills, the statistician must demonstrate great computer agility, have a high awareness of issues of data ethics and control of their dissemination, and possess solid knowledge of the application fields. It is essential that the training of statisticians is strategically thought out so that they can be reactive and dynamic in the face of the changes and upheavals they will be confronted with in the context of data revolution and big data. Their training should reinforce the statistical literacy dimension with a view to reducing the gap between producers and users.

\section{Acknowledgments}

The author would like to thank Wilfrid Granger and two anonymous referees for their valuable and many helpful comments on the first draft of this paper. I would like also to thank Pieter and the guest editorial team of this special issue for their guidance's. I would like to extend my gratitude to colleagues of RESA for comments and $\mathrm{M}$ Blafon Herman for the proof reading of the language. I alone am responsible for any errors.

\section{References}

[1] Devarajan S. Africa's Statistical Tragedy, The Review of Income and Wealth 2013, 59(9-15).

[2] United Nations. Economic Commission for Africa. The African centre for statistics: better statistics for better development outcomes. Addis Ababa 2016; https://hdl.handle.net/ $10855 / 23550$

[3] CUA, CEA, BAD, Stratégie pour l'harmonisation des statistiques en Afrique (SHaSA), Addis-Abeba, Commission de l'Union africaine. 2010.
[4] United Nations. Economic Commission for Africa. Addis Ababa plan of action for statistical development in Africa in the 1990s. Addis Ababa; 1990; https://hdl.handle.net/10855/3798.

[5] United Nations. Economic Commission for Africa, Conclusions and Recommendations of the First Meeting of the Statistical Commission for Africa (StatCom-Africa I), The African Statistical Journal, 2008, Volume 6.

[6] Development Data Group. The Marrakech Action Plan for Statistics: Better Data for Better Results An Action Plan for Improving Development Statistics; Second International Roundtable on Managing for Development Results, Marrakech (Morocco) 2004.

[7] Pali L. Statistical Development in Africa in the context of the Global Statistical System. Statistical Commission Thirty-ninth session, Regional statistical development in Africa. 2008.

[8] Odwee J, ISAE, ADB. Statistical Training at the Institute of Statistics and Applied Economics, Makerere University, 2005. https://silo.tips/download/statistical-training-at-the-instituteof-statistics-and-applied-economics-makere.

[9] United Nations. Economic Commission for Africa. Report of the Second Conference of African statisticians: Tunis, Tunisia, 26 June-7 July 1961. Addos Ababa; 1961. https://hdl.handle. net/10855/16540.

[10] Charoy X, Diop L. Le CESD - paris: au service de la formation statistique, Statéco, 2006, 100: 63-69.

[11] Gérard Gié, Renaud Decoster. Les appuis de la France et de la Commission Européenne aux écoles africaines de statistique: Évaluation rétrospective (1994-2002), Ministère des affaires étrangères, 2003.

[12] Woodward M, Dourmashkin N, Twagirumukiza E, Mbago MCY, Ferreir Da Cunha AS. Statistics training in eastern and southern Africa: a study of supply and demand, The Statistician, 1997; 46(3): 371-386.

[13] Ching'anda EF, Ntozi JPM. Training employees for african statistical offices, International Statistical Review/Revue Internationale de Statistique, 1998; 66(2): 235-244.

[14] IEG (Independent Evaluation Group). Marrakech Action Plan for Statistics, Partnership in Statistics for Development in the 21st Century, and Trust Fund for Statistical Capacity Building. Global Program Review2; 2011, Vol. 5, Issue 3.

[15] ECA. Addis Ababa Plan of Action for Statistical Development in Africa in the 1990s. 1990.

[16] ECA. A Strategy for the Implementation of the Addis Ababa Plan of Action for Statistical Development in Africa in the 1990s. 1992.

[17] Enoch C, Kibuka R. The General Data Dissemination System (GDDS) - A reflection on its First 12 years and Plans for Taking it Forward, IMF Working paper, WP/09/278, 2009. doi: 10.5089/9781451874235.001.

[18] Lufumpa CL, Mouyelo-Katoula M. Strengthening Statistical Capacity in African Countries under the Framework of the International Comparison Program for Africa (ICP-Africa), African Statistical Journal, vol 1, 2005.

[19] OPM. Evaluation of the Implementation of the Paris Declaration: Thematic Study - Support to Statistical Capacity Building, Synthesis Report. 2009.

[20] Cling J-P, Razafindrakoto M, Roubaud F. Les Nouvelles Stratégies internationales de lutte contre la pauvreté, Paris, Economica/IRD. 2003.

[21] Laurent C, Baudry J, Berriet-Solliec M, Kirsch M, Perraud D, Tinel B, Trouvé A, Allsopp N, Bonnafous P, Burel F, José Carneiro M, Giraud C, Labarthe P, Matose F, Ricroch A. Pourquoi s'intéresser à la notion d'evidence-based policy? Tiers Monde, 2009, CC(4): 853-873. 
[22] Bédécarrat F, Cling JP, Roubaud F. Gouverner par les nombres, Révolution des données et enjeux de la statistique en Afrique: Introduction thématique, Afrique Contemporaine 2016/2 n ${ }^{\circ}$ 258: 9-23. Available from: https://www.cairn.info/ revue-afrique-contemporaine-2016-2-page-9.htm.

[23] Nations unies. Pour un nouveau partenariat mondial: vers l'éradication de la pauvreté et la transformation des économies par le biais du développement durable, rapport du Groupe de personnalités de haut niveau chargé du programme de développement pour l'après-2015, New York. 2013.

[24] United Nations Economic and Social Council and the African Union, Strategy for the Harmonisation of Statistics in Africa. SHaSA II (2017-2026), March 2017.

[25] Hila Zahavi \& Yoav Friedman. The Bologna Process: an international higher education regime, European Journal of Higher Education, 2019 9:1, 23-39. doi: 10.1080/21568235.2018. 1561314.
[26] Ntozi James PM. Training Statisticians for Africa: Has the programme succeeded? Int. Statistical Inst.: Proc. 58th World Statistical Congress, 2011, Dublin (Session CPS022).

[27] Atherton J. Learning and Teaching; Cognitive Theories of Learning. 2011 [On-line: UK], Available from http://www. learningandteaching.info/learning/cognitive.htm.

[28] Crouzel L, Meunier N, et Paccoud T. La statistique publique en Afrique francophone: plaidoyer pour un dialogue renové avec les usagers, Statéco, 2018; 112: 69-78. Avalaible from http://dial.ird.fr/media/ird-sites-d-unites-de-recherche/dial/do cuments/publications/stateco/112/stateco-06-crouzel. 